\title{
VIRTUAL INSTRUMENTATION BASED ACTIVE FIN CONTROL FOR ROLL STABILIZATION
}

\author{
V. Anantha Subramanian', G. Asokumar' ${ }^{1}$ and Thaju Mohamed ${ }^{2}$ \\ ${ }^{1}$ Department of Ocean Engineering, Indian Institute of Technology Madras, Chennai- 60036, India. Ph. 0091-44- \\ 22574812, e-mail: subru@,iitm.ac.in, gak iitm@yahoo.com \\ ${ }^{2}$ Department of Electrical Engineering, Indian Institute of Technology Madras, Chennai-60036, India
}

\begin{abstract}
The objective of this work is to develop a non-traditional strategy for providing control of ship roll motion in a seaway using active fins. This is based on a multidisciplinary approach. It consists of the assessment of the hydrodynamic coefficients of a ship using a numerical package [SEDOS], representation of the hydrodynamic coefficients by suitable polynomial functions, identification of the time dependent fundamental frequency in the roll disturbance signal sample, generation of control signal for an appropriate fin angle based on the fin lift characteristics of the chosen fin and employment of feedback control to maintain the fin at the appropriate angle for maximum control. Once the ship based hydrodynamic coefficients are generated, the entire control algorithm is developed in the virtual instrumentation mode using LabVIEW environment. One of the disadvantages of the traditional stabilizer system is the enormous hardware involved in the controllers and instrumentation panels, which makes maintenance and troubleshooting difficult. With the help of virtual instrumentation, design of the stabilization controller and instrumentation panels can be carried out much more effectively, in comparison with the traditional hardware approach.
\end{abstract}

Key words: Roll stabilization, Active fin control, Virtual instrumentation

\section{NOMENCLATURE:}

$\alpha_{\mathrm{t}} \quad$ Angle of attack, deg

$\theta \quad$ Angle encountered by fin with hull vertical plane, deg

C.G Centre of Gravity, $m$

A Roll virtual mass moment of inertia, $t-m^{2}$

B Roll damping coefficient, $\mathrm{t}-\mathrm{m}^{2} / \mathrm{sec}$

C Roll restoring moment coefficient, $\mathrm{kN}-\mathrm{m}$

$\mathrm{C}_{\mathrm{L}} \quad$ Coefficient of lift

$\mathrm{C}_{\mathrm{L} \alpha} \quad$ Lift slope coefficient, $\mathrm{rad}^{-1}$

$\mathrm{V} \quad$ Ship speed, $\mathrm{m} / \mathrm{s}$

$\mathrm{S}_{\mathrm{f}} \quad$ Fin profile area, $\mathrm{m}^{2}$

$\rho \quad$ Density of seawater, $t / \mathrm{m}^{3}$

$\omega_{\mathrm{e}} \quad$ Encounter frequency, $\mathrm{rad} / \mathrm{s}$ 


\section{Introduction}

Motion stabilization devices are often adopted in vessels in order to reduce their motions in a seaway. The main oscillations of heave, pitch and roll are the principal reasons for limiting the operability of a vessel, and also for causing adverse influence on human comfort and habitability. Devices used for stabilization may be passive or active. Any successful device requires combined consideration of the hydrodynamic forces as well as control engineering. With the help of stabilizers, the amplitude, rate and acceleration of the motion as well as some dynamic effects i.e., deck wetness and slamming can be reduced considerably. There are three well known ways to reduce forced motions. They are damping stabilization, tuning stabilization and equilibrium stabilization. The present work is based on the principle of equilibrium stabilization with active stabilizer fins using virtual instrumentation based control. The term "virtual instrumentation" is used to represent a PC based control system which is used to acquire data from physical transducers and then manipulate them in specific ways using a very high level graphical environment. In the graphical environment, symbolic icons are used that operate in the same way as real instruments do. A non-traditional strategy is presented to provide motion control for ship roll motion using fins. The basic ship motion characteristics are obtained by means of a prediction program (SEDOS). Using the fin performance characteristics, the countering forces required and the consequent fin movement are achieved in a control loop.

One of the disadvantages of the traditional stabilizer system is the enormous hardware involved in the controllers and the instrumentation panels, which makes maintenance and troubleshooting difficult. With the help of virtual instrumentation, the design of the stabilization controller with virtual panels can be performed with a great deal of flexibility and effectiveness. In this work, the control has been designed and implemented using virtual instrumentation in the LabVIEW environment.

\section{Motivation}

Fin stabilizers have been used for motion stabilization typically in passenger ships and warships. Conolly (1968) developed a linear theory to predict rolling motions under the action of active stabilizers. Lloyd (1974) made comparisons of Conolly's prediction with laboratory model measurements and quantified the interaction coupling effects between roll, sway and yaw motions. Gunsteren (1974) developed a method for the design of stabilizer including the dynamic effects of the fins and the ship. Tsuyoshi et al. (1994) investigated the influence of fin area and the control method on the reduction of roll with the fin stabilizer. Sgobbo and Parsons (1999) studied the effects of the rudder and fins on the rolling motion of the ship using three degree of freedom (3-DOF) model. They presented a set of equations which give the effect of fins and rudder on the damping matrix and the roll added mass moment of inertia matrix. Significant roll reduction can be achieved using the MIMO rudder/fin controller. Samoilescu and Radu (2002) presented the control engineering aspects of a fin system which takes into account roll velocity, roll acceleration, roll angle, natural list and ship speed in a feedback control system. Virtual instrument based control and measurements are being increasingly used as versatile, flexible technique [Rahman and Pichlik, 1999] in many control engineering applications. In the light of the above developments and based on the hydrodynamic coefficients of the ship and the fins, a control algorithm is developed. Based on the input from a roll angle sensor and knowledge of ship hydrodynamic coefficients as well as fin lift characteristics, programming has been undertaken for virtual instrumentation in the LabVIEW environment. Therefore in place of involved hardware instrumentation and circuits for achieving feedback control, a compact software based control is presented. The virtual instrumentation integrates the hydrodynamic characteristics of the ship with correct choice of fin angle in a feed back control loop.

\section{Analytical Motion Prediction and Motion Control Equation}

A motion analysis package namely SEDOS [Soeding, 1988] has been used for obtaining the ship hydrodynamic coefficients for motion prediction. The method is based on strip theory. The program performs calculation for the motion analysis of ship in regular waves and in natural, stationary seas. Most strip theory methods do this by solving the boundary value problems for the velocity potential 
functions for infinitely long, semi submerged hull forms. The effect of ship speed on hydrodynamic coefficients is taken into account by assuming that coupling between the steady contribution and the harmonically oscillating fluid disturbance can be neglected. Thus the three dimensional response and wave exciting forces for a ship with forward speed are obtained by lengthwise integration of the zero speed, two-dimensional sectional response and wave exciting forces. Though the program is originally developed for twin hulls to predict the motions in 6-DOF, with modifications made in the input files, the same program can be used for monohulls.

The strip theory is used to calculate ship motions. The method uses formulation of equations of motion limited to rigid-body subjected to harmonic exciting forces and moments due to free-surface waves with small wave slopes. The method is developed under the assumption of infinite water depth. The ship is assumed to maintain a constant mean forward speed and a straight mean course. The submerged portion of the hull is assumed to be slender enough for the rate of lengthwise variation of hydrodynamic pressures to be small. The method takes into account external forces and moments acting on the ship. These comprise effects of gravity, buoyancy, pressure due to water particle motions (Froude-Krylov forces), radiation of waves due to the ship's motions, scattering (i.e., diffraction) of incident waves and damping due to viscous lift. As part of the validation for response for a monohull, analysis and comparison have been carried out with published experimental values for a particular ship [Korkut et al., 2004]. The comparison is shown in Figure 2.

\subsection{Formulation of motion control equation using fins}

The general roll motion equation in single degree of freedom (SDOF) can be written as

$$
I_{x x} \ddot{\theta}+B \dot{\theta}+C \theta=E(t)
$$

Where

$$
\begin{aligned}
& \ddot{\theta}=\text { roll acceleration }\left(\mathrm{rad} / \mathrm{s}^{2}\right) \\
& \dot{\theta}=\text { roll velocity }(\mathrm{rad} / \mathrm{s}) \\
& \theta=\text { roll displacement }(\mathrm{rad}) \\
& \mathrm{I}_{\mathrm{xx}}=\text { virtual mass moment of inertia }\left(\mathrm{t}-\mathrm{m}^{2}\right) \\
& \mathrm{B}=\text { damping coefficient }\left(\mathrm{t}-\mathrm{m}^{2} / \mathrm{s}\right) \\
& \mathrm{C}=\text { restoring moment }(\mathrm{kN}-\mathrm{m}) \\
& \mathrm{E}(\mathrm{t})=\text { wave exciting moment }(\mathrm{kN}-\mathrm{m}) .
\end{aligned}
$$

In linear theory, the harmonic responses of the vessel $\eta_{j}(t)$ [Lewis, 1989] is directly proportional to the amplitude of exciting moment/force at the same frequency with some phase shift. Consequently the ship motions will have the form

$\eta_{j}(\mathrm{t})=\left|\eta_{j}\right| \cos \left(\omega_{\mathrm{e}} \mathrm{t}+\sigma_{\mathrm{j}}\right)=>\left|\eta_{j}\right| \mathrm{e}^{\mathrm{i} \omega \mathrm{e} t}$ and $\mathrm{E}(\mathrm{t})=\left|E_{j}\right| \cos \left(\omega_{\mathrm{e}} \mathrm{t}+\sigma_{\mathrm{j}}\right)=>\left|E_{j}\right| \mathrm{e}^{\mathrm{i} \omega \mathrm{e} \mathrm{t}}$

Differentiation with respect to time $(\mathrm{t})$ gives

$$
\dot{\eta}_{j}(t)=\mathrm{i} \omega_{\mathrm{e}}\left|\eta_{j}\right| \mathrm{e}^{\mathrm{i} \omega \mathrm{e} \mathrm{t}} \text { and } \ddot{\eta}_{j}(t)=-\omega_{\mathrm{e}}^{2}\left|\eta_{j}\right| \mathrm{e}^{\mathrm{i} \omega \mathrm{e} \mathrm{t}}, \mathrm{j} \text { is the motion mode. }
$$

Assuming $\theta=\eta_{4}, \mathrm{~m}_{44}=$ mass moment of inertia for roll and $\mathrm{E}_{4}=$ wave exciting moment, Eqn (1) gets modified as follows.

$$
\begin{aligned}
& {\left[-\left(\mathrm{a}_{44}+\mathrm{m}_{44}\right) \omega_{\mathrm{e}}^{2}+\mathrm{iB}_{44} \omega_{\mathrm{e}}+\mathrm{C}_{44}\right] \eta_{4}=\mathrm{E}_{4} \text { This is rewritten as }} \\
& {\left[-\omega_{\mathrm{e}}^{2}\left(\mathrm{a}_{44}+\mathrm{m}_{44}\right)+\mathrm{i} \omega_{\mathrm{e}} \mathrm{B}_{44}+\mathrm{C}_{44}\right] \eta_{4}=\mathrm{E}_{4} \quad \Rightarrow>\left[\mathrm{C}_{44}-\omega_{\mathrm{e}}^{2} \mathrm{~m}_{44}-\mathrm{b}_{1}-\mathrm{ib} \mathrm{b}_{2}\right] \eta_{4}=\mathrm{E}_{4}}
\end{aligned}
$$

where $\mathrm{b}_{1}=\omega_{\mathrm{e}}{ }^{2} \mathrm{a}_{44}, \mathrm{~b}_{2}=-\omega_{\mathrm{e}} * \mathrm{~B}_{44}$ and $\mathrm{S}_{44}=\mathrm{C}_{44}$ restoring coefficient. 
Introducing $\mathrm{b}_{44}=\mathrm{b}_{1}+\mathrm{ib}$, the roll motion is

$\left(\mathrm{S}_{44}-\mathrm{b}_{44}-\omega_{\mathrm{e}}^{2} * \mathrm{~m}_{44}\right) \eta_{4}=\mathrm{E}_{4}$

If we consider 3 degree of freedom (3DOF) model (sway, roll, yaw), the above equation can be written in matrix form as follows:

$$
\left([\mathrm{S}]-[\mathrm{b}]-\omega_{\mathrm{e}}{ }^{2 *[\mathrm{~m}])\left[\eta_{\mathrm{j}}\right]}=\left[\mathrm{E}_{\mathrm{j}}\right]\right.
$$

where $\mathrm{j}=2,4,6$;

Equation (3) represents 3-DOF model for sway, roll, yaw in coupled condition (without fin). By incorporating the fin effect into the motion equation (3) [Sgobbo and Parsons, 1999], the above equation gets modified as follows:

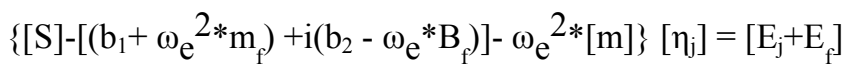

In which, $\mathrm{m}_{\mathrm{f}}, \mathrm{B}_{\mathrm{f}}$ and $\mathrm{E}_{\mathrm{f}}$ are fin induced mass, damping and moment/force matrices respectively. It is given in matrix form as follows.

$$
\mathrm{m}_{\mathrm{f}}=\left[\begin{array}{ccc}
\mathrm{A}_{22 \mathrm{f}} & \mathrm{A}_{24 \mathrm{f}} & \mathrm{A}_{26 \mathrm{f}} \\
\mathrm{A}_{42 \mathrm{f}} & \mathrm{A}_{44 \mathrm{f}} & \mathrm{A}_{46 \mathrm{f}} \\
\mathrm{A}_{62 \mathrm{f}} & \mathrm{A}_{64 \mathrm{f}} & \mathrm{A}_{66 \mathrm{f}}
\end{array}\right] \quad \begin{aligned}
& \mathrm{A}_{22 \mathrm{f}}=(-2) \mathrm{M}_{\mathrm{f}}, \mathrm{A}_{24 \mathrm{f}}=(-2) \mathrm{M}_{\mathrm{f}} \mathrm{R}_{\mathrm{f}}, \mathrm{A}_{26 \mathrm{f}}=(-2) \mathrm{M}_{\mathrm{ff}} 1_{42 \mathrm{f}} \\
& \mathrm{A}_{42}=(-2) \mathrm{M}_{\mathrm{f}} \mathrm{R}_{\mathrm{f}}, \mathrm{A}_{44 \mathrm{f}}=(-2) \mathrm{M}_{\mathrm{f}} \mathrm{R}_{\mathrm{f}}^{2}, \mathrm{~A}_{46} \mathrm{f}=(-2) \mathrm{M}_{\mathrm{f}} \mathrm{R}_{\mathrm{f}} 1_{\mathrm{f}} \\
& \mathrm{A}_{62 \mathrm{f}}=(-2) \mathrm{M}_{\mathrm{f} f}, \mathrm{~A}_{64 \mathrm{f}}=(-2) \mathrm{M}_{\mathrm{f}} \mathrm{R}_{\mathrm{ff}}, \mathrm{A}_{66 \mathrm{f}}=(-2) \mathrm{M}_{\mathrm{f} f}{ }_{\mathrm{f}}^{2}
\end{aligned}
$$

where

$\mathrm{M}_{\mathrm{f}}=(\mathrm{b} / 2)^{*} \mathrm{c}_{\mathrm{m}} * \rho^{*}(2 * \pi) / 4, \mathrm{c}_{\mathrm{m}=\text { mean chord, }(\mathrm{b} / 2)-\text { mean span }}$

$$
\begin{aligned}
& B_{f}=\left[\begin{array}{lll}
B_{22 f} & B_{24 f} & B_{26 f} \\
B_{42 f} & B_{44 f} & B_{46 f} \\
B_{62 f} & B_{64 f} & B_{66 f}
\end{array}\right] \\
& E_{f}=\left[\begin{array}{l}
Y_{\alpha} \\
K_{\alpha} \\
N_{\alpha}
\end{array}\right] B_{22 f}=(-\rho) S_{f} V C_{L \alpha} \cos (\theta), \\
& B_{24 f}=(-\rho) S_{f} V C_{L \alpha} \cos (\theta) R_{v f} \\
& B_{26 f}=(-\rho) S_{f} V C_{L \alpha} \cos (\theta) l_{f} \\
& B_{42 f}=(-\rho) S_{f} V C_{L \alpha} \cos (\theta) R_{v f} \\
& B_{44 f}=(-\rho) S_{f} V C_{L \alpha} R_{f}^{2} \\
& B_{46 f}=(-\rho) S_{f} V C_{L \alpha} \cos (\theta) l_{f} R_{V f} \\
& B_{62 f}=(-\rho) S_{f} V C_{L \alpha} \cos (\theta) l_{f} \\
& B_{64 f}=(-\rho) S_{f} V C_{L \alpha} \cos (\theta) l_{f} R_{V f} \\
& B_{66 f}=(-\rho) S_{f} V C_{L \alpha} \cos (\theta) l_{f}^{2}
\end{aligned}
$$

$\mathrm{Y}_{\alpha}=(-\rho) \mathrm{S}_{\mathrm{f}} \mathrm{V}^{2} \mathrm{C}_{\mathrm{L} \alpha} \cos (\theta) ; \mathrm{K}_{\alpha}=(-\rho) \mathrm{S}_{\mathrm{f}} \mathrm{V}^{2} \mathrm{R}_{\mathrm{f}} \mathrm{C}_{\mathrm{L} \alpha} ; \mathrm{N}_{\alpha}=(-\rho) \mathrm{S}_{\mathrm{f}} \mathrm{V}^{2} \mathrm{C}_{\mathrm{L} \alpha} \cos (\theta) \mathrm{l}_{\mathrm{f}}$

Where

$\mathrm{S}_{\mathrm{f}}=$ profile area of the pair of fin $\left(\mathrm{m}^{2}\right)$.

$\mathrm{R}_{\mathrm{vf}}=$ vertical component of lever arm. i.e. the vertical distance from the ship centre of gravity to the centre of pressure on the fin

$\mathrm{R}_{\mathrm{f}}=$ lever arm, . i.e. the distance from the ship centre of gravity to the centre of pressure on the fin

$\mathrm{V}=\operatorname{ship} \operatorname{speed}(\mathrm{m} / \mathrm{s})$

$\rho=$ water density $\left(\mathrm{t} / \mathrm{m}^{3}\right)$

$\alpha_{t}=$ Fin angle of attack

$\theta=$ angle between hull vertical plane and fin

$1_{\mathrm{f}}=$ longitudinal distance between the roll centre and fin centre of pressure (see Figure 1) 
The complete sway, roll, yaw coupled equation with fin related terms can be thus obtained. In a simplified form, the sway, yaw terms may be neglected. The above scheme has been applied in the case of a yacht with a single hard chine hull form as shown in Fig.4. Motion has been first predicted for beam sea regular waves without any fin control using the above equations as shown in Fig.5. For an assumed fin location in the ship, the stabilized motion under optimum fin control has been analyzed and shown in Fig.6.The main ship particulars are given in Table 1. The particulars of the fin (NACA 0015) are given in Table 2 .

For the chosen fin, the lift characteristic is shown in Fig.3. The fin lift coefficient is linear up to $16^{0}$. Using virtual instrumentation in the LabVIEW environment, simulation studies have been conducted to demonstrate the deployment of the control algorithm and system.

Table 1: Main particulars of ship for simulation studies

\begin{tabular}{|l|l|c|}
\hline \multicolumn{1}{|c|}{ Particulars } & $\begin{array}{c}\text { Prototyp } \\
\text { e }\end{array}$ & $\begin{array}{c}\text { Model } \\
\text { (Scale 1:20) }\end{array}$ \\
\hline LBP & $38 \mathrm{~m}$ & $1.9 \mathrm{~m}$ \\
\hline Beam & $8.2 \mathrm{~m}$ & $0.41 \mathrm{~m}$ \\
\hline Draft $(\mathrm{T})$ & $1.7 \mathrm{~m}$ & $0.085 \mathrm{~m}$ \\
\hline Depth $(\mathrm{D})$ & $5.36 \mathrm{~m}$ & $0.268 \mathrm{~m}$ \\
\hline $\mathrm{K}_{\mathrm{xx}}$ & $3.28 \mathrm{~m}$ & $0.164 \mathrm{~m}$ \\
\hline $\mathrm{K}_{\mathrm{yy}}$ and $\mathrm{K}_{\mathrm{zz}}$ & $11.4 \mathrm{~m}$ & $0.57 \mathrm{~m}$ \\
\hline Displacement & $183.5 \mathrm{t}$ & $23 \mathrm{~kg}$ \\
\hline Design speed & $13 \mathrm{knots}$ & $1.5 \mathrm{~m} / \mathrm{s}$ \\
\hline
\end{tabular}

Table 2: Main particulars of fin

\begin{tabular}{|l|l|l|}
\hline Particulars & Prototype & $\begin{array}{c}\text { Model } \\
\text { (Scale } \\
\mathbf{1 : 2 0 )}\end{array}$ \\
\hline Type & $\begin{array}{l}\text { NACA } \\
0015\end{array}$ & $\begin{array}{l}\text { NACA } \\
0015\end{array}$ \\
\hline Aspect ratio & 1.0 & 1.0 \\
\hline Mean span & $1.87 \mathrm{~m}$ & $0.0935 \mathrm{~m}$ \\
\hline Mean chord & $1.87 \mathrm{~m}$ & $0.0935 \mathrm{~m}$ \\
\hline Profile area & $3.5 \mathrm{~m}^{2}$ & $0.0087 \mathrm{~m}^{2}$ \\
\hline
\end{tabular}

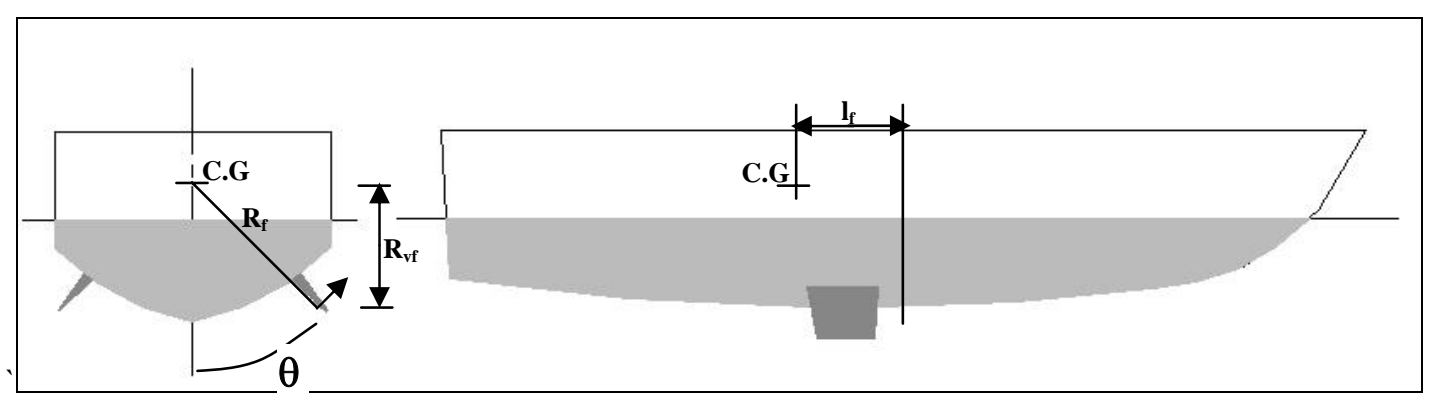

Figure 1: Fin location

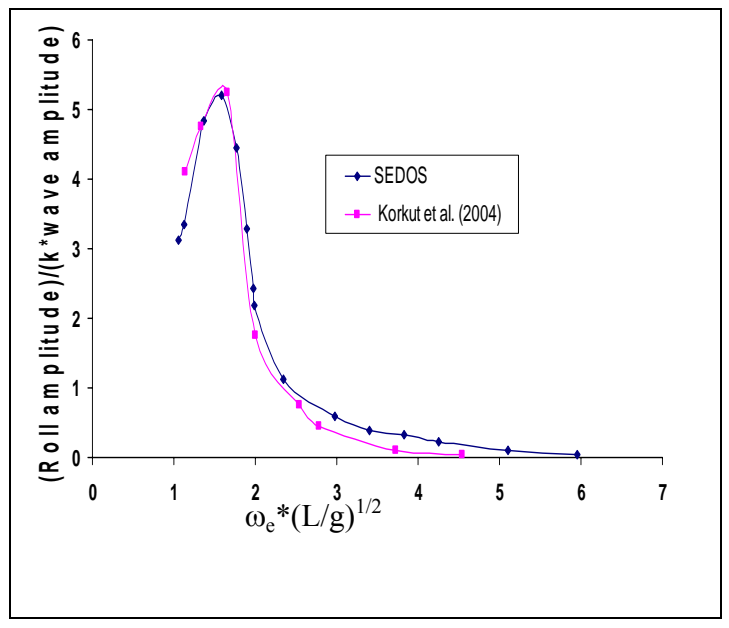

Figure 2: Roll response for Ro-Ro Ship

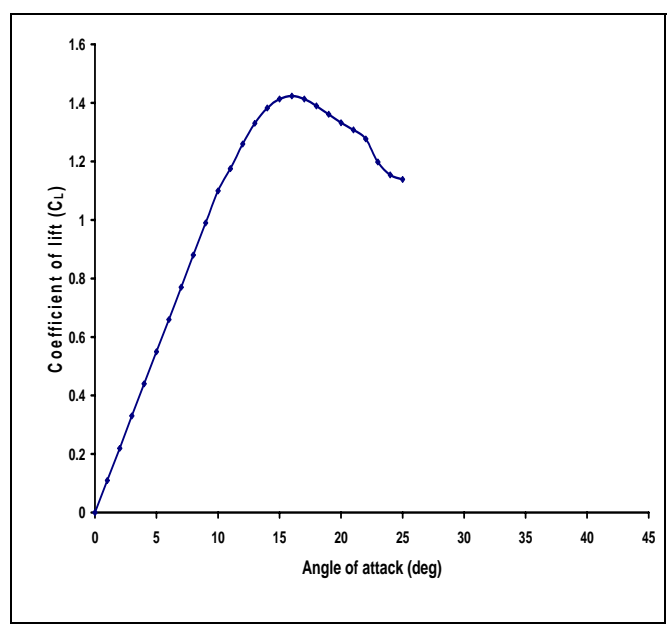

Figure 3: Fin characteristic curve 


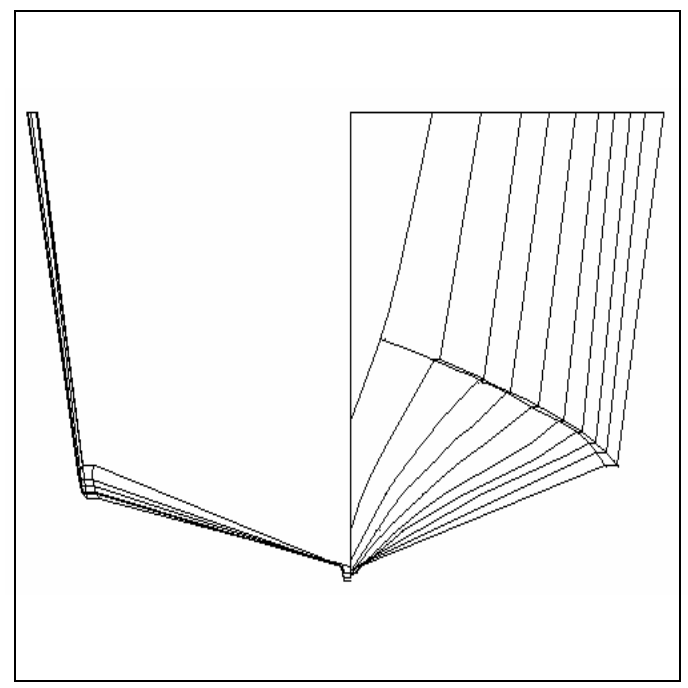

Figure 4: Body plan of the single hard chine hull

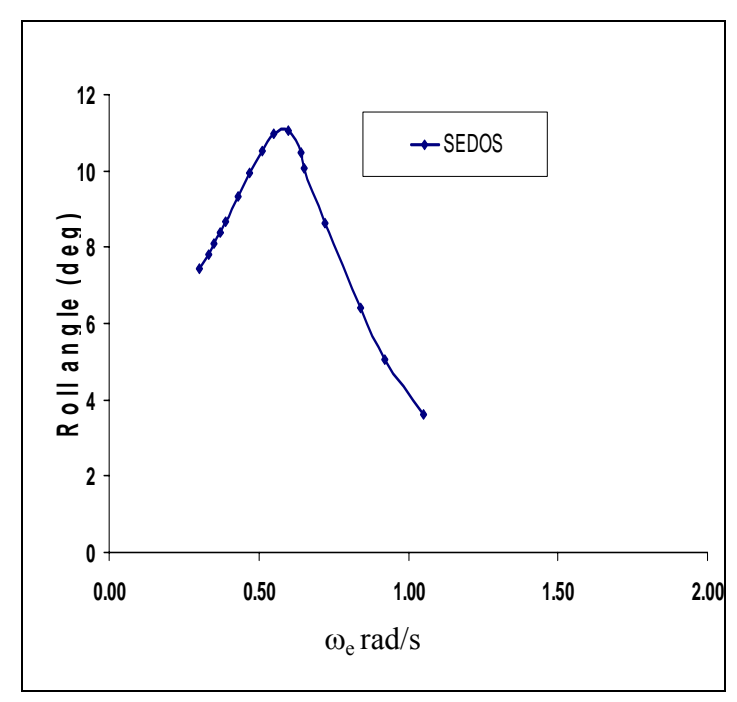

Figure 5: Roll response for single chine yacht hull

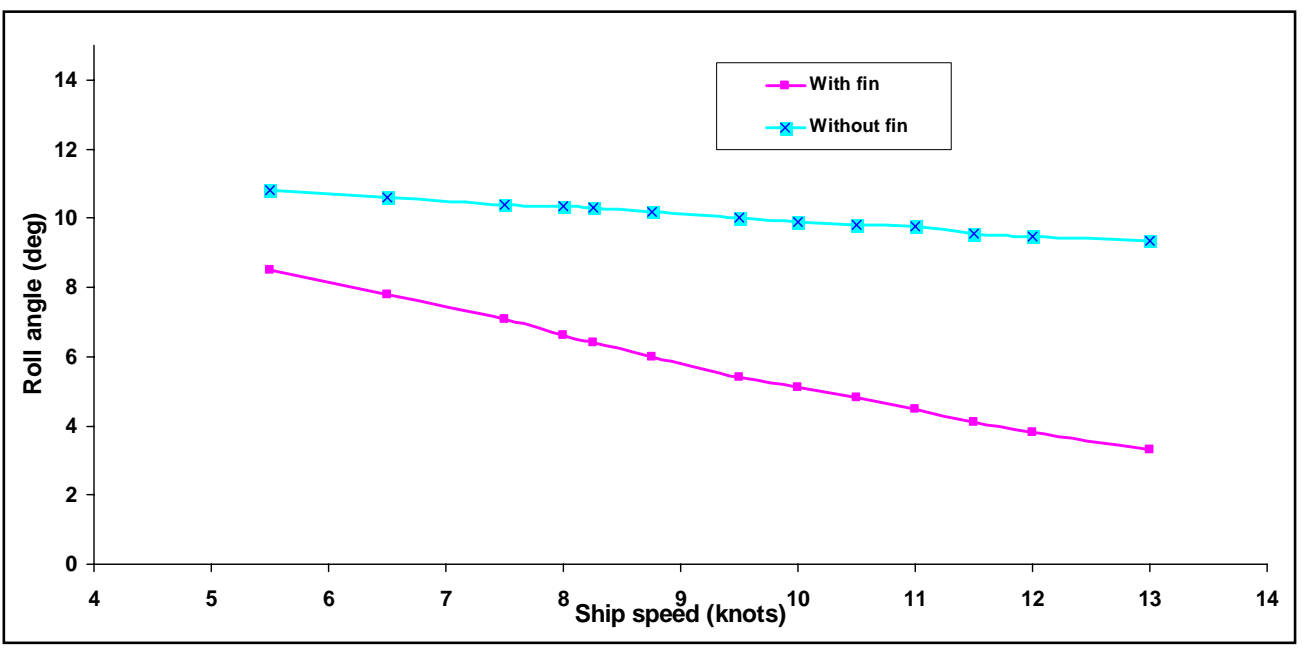

Figure 6: Roll reduction by analytical prediction for yacht hull

\section{Virtual Instrumentation Control Algorithm}

The objective of the control system is to activate the fin in order to minimize the roll motion and bring it to the ideal zero value. In a practical sense, a significant roll reduction is quite feasible depending on the refinement and precision of the control logic. To this end, virtual instrumentation has been used in the present system. Virtual instrumentation refers to the use of general-purpose computers and workstations, in combination with data collection hardware devices (sensors), and virtual instrumentation software, to construct an integrated instrumentation system. In such a system the roll sensing device (clinometer), which incorporates the sensing element for detecting changes in the ship rolling motion, is intimately, coupled to the computer. The acquired data is processed in a specific way so that it will generate the control signal for fin activation. The essential components of the control system are as follows:

i) Clinometer ii) virtual instrumentation, which generates the control signal iii) servo amplifier iv) actuator v) mechanical linkage 
The fin control system block diagram is shown in Fig. 7 .The block diagram is divided into 5 modules namely,

1) Sensor, 2) Signal conditioner, 3) Control signal generator, 4) Comparator , 5) Actuator.

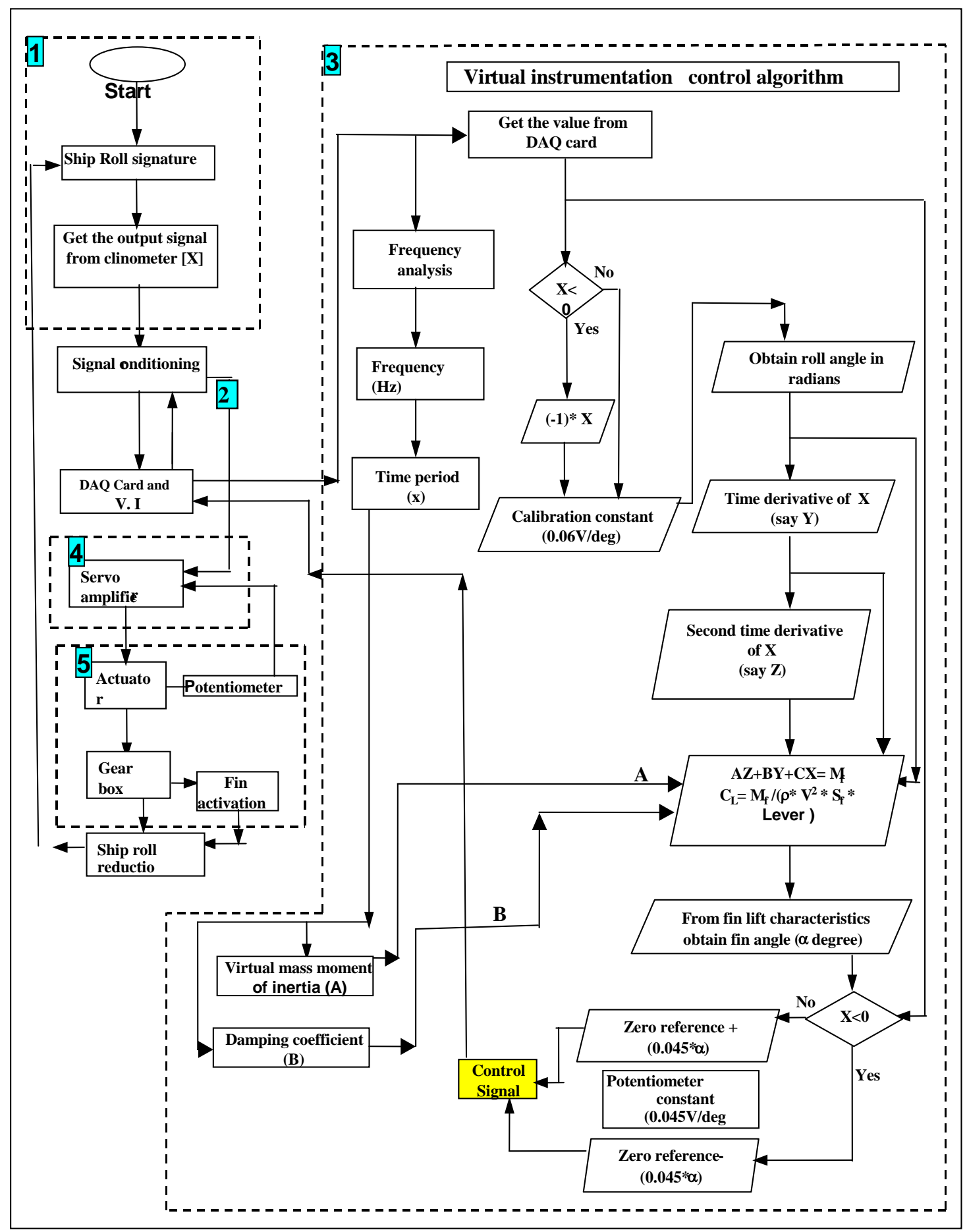

1 Sensor 2 Signal conditioner 3 Control signal generation 4 Comparator 5 Actuator

Figure 7: Control algorithm block diagram 
The clinometer senses the ship roll signature [Block 1 in Figure 7] and sends the analog signal to the signal-conditioning module [Block 2]. Its main functions are amplification, isolation and simultaneous sampling. This is an essential component when dealing with high voltages, noisy environment, and extreme high and low signals. The conditioned analog signal is given to the data acquisition card plugged into the laptop computer [Intel processor clocked at $650 \mathrm{MHz}$ and having $128 \mathrm{MB}$ of RAM]. From the data acquisition card the signal in digitized format is further processed. The next module [Block 3] generates the control signal which is given to the servo amplifier [Block 4]. This unit serves as a comparator for the signal from the controller and the potentiometer which senses fin positions continuously as a feedback signal. Any deviation of the two values is amplified as error signal. This amplified error signal is given to the actuator [Block 5] and the polarity of the error signal determines which way the correction needs to be made. In the present work, the proportional control mode was adopted in view of its simplicity and reliability. The control strategy is a single input-single output type. It is seen that the roll motion of the vessel is now dependent on the input sea conditions as well as response of the vessel to fin action. The graphical environment (LabVIEW) includes all the tools needed for data acquisition, analysis, storage and presentation. Therefore, by "wiring" together objects that perform different functions, it is possible to create specific virtual instruments. The utilization of a software based data acquisition system has the advantage that all the engineering units can be converted on a software basis. The program with the functions in the virtual instrumentation are shown in submodules 3.1 to 3.7 in Figure 8a, 8b, 8c.

Module 3.1 facilitates flexible choice of sampling rate and number of samples taken for analyzing average roll value and fundamental frequency in the sample. Signal plots may be obtained directly from this module.

Module 3.2 compares the roll angle with the desirable ideal value (zero degree roll).

Module 3.3 detects the fundamental frequency in the signal sample taken and therefore its fundamental time period.

Module 3.4 stores the ship hydrodynamic coefficients (virtual mass moment of inertia and the damping coefficient) and obtains appropriate frequency based coefficients from stored polynomial based data functions.

Module 3.5 performs roll signal differentiation to obtain velocity and acceleration terms to combine with the hydrodynamic coefficients and obtain the correct fin counter moments.

Module 3.6 produces the appropriate voltage for fin activation. It receives input from module 3.7, which contains fin geometry based data and therefore calculates the appropriate fin angle. The Fig.8a, $8 \mathrm{~b}, 8 \mathrm{c}$ elucidate the full control algorithm and data flow in the feedback controlled system.

Two control algorithms are considered for executing the control loop namely

(i) fixed coefficients based control loop and

(ii) frequency dependent coefficients based control loop

\subsection{Control algorithm using fixed coefficients in the control loop}

The virtual mass moment of inertia (A) and damping (B) values related to the ship motion are given in Table.3. A ship in a seaway is subjected to excitation by waves, which may occur at, or outside the resonance region. At resonance frequency, the largest roll motions occur. However, regardless of whether the excitation is at resonance frequency or other frequencies, once the excitation source is removed, the ship would quickly settle to its natural roll frequency till the energy is dissipated. Therefore the choice of hydrodynamic coefficients associated with the resonance frequency roll may be 
quite effective in tackling the control of roll motion. The mechanism of the control loop is explained below.

Referred to Table 3, for a sea-wave period $\mathrm{T}=17.9 \mathrm{~s}$ which is outside the natural period of roll for the vessel considered, the corresponding sea frequency is $0.35 \mathrm{rad} / \mathrm{s}$.

The calculated values of virtual mass moment of inertia (A) $=3900 \mathrm{t}-\mathrm{m}^{2}$

Damping coefficient $(B)=2813 \mathrm{t}-\mathrm{m}^{2} / \mathrm{s}$

Roll excitation moment $=9810 \mathrm{Nm}$.

Associated with the fin lift characteristic curve in Fig.3, the lift coefficient is $\mathrm{C}_{\mathrm{L}}=1.25$ at a required fin angle $\alpha=13.7^{0}$. The fin lift coefficient and fin angle combination have been arrived at by solving the roll motion equation for ideal roll reduction and using the hydrodynamic coefficients associated with roll resonance frequency (fixed values). Hence for simplicity this algorithm used fixed coefficients $[A=$ $\left.3555 \mathrm{t}-\mathrm{m}^{2}, \mathrm{~B}=3450 \mathrm{t}-\mathrm{m}^{2} / \mathrm{sec}\right]$. If actual frequency based coefficients are used $\left[\mathrm{A}=3900 \mathrm{t}-\mathrm{m}^{2}, \mathrm{~B}=2813 \mathrm{t}-\right.$ $\left.\mathrm{m}^{2} / \mathrm{sec}\right]$, then the required fin angle is $12.42^{\circ}$. Use of fixed coefficients would result in an excess fin angle and therefore excessive roll correction by nearly a degree. This is corrected in the next loop after taking feed back deviation from the comparator. Therefore it is seen that using the fixed values of the coefficients at resonance frequency still results in a rapid correction of the roll angle. The time in the computation loop of the LabVIEW controller is of the order of $10 \mathrm{~ms}$. The activation of the mechanical system relating to fin movement with the associated inertia of the gear and shafting is much larger. Once the first fin movement is executed, the error is recognized by the feed-back comparator, then sent back to the computational loop and the second corrective signal is given. The second movement is much smaller than the first, therefore the time delay would be much smaller. It is seen that the system quickly settles down to the execution of the correct fin angle.

Therefore by example, it has been shown that even outside the frequency of natural roll, the fin stabilization system works effectively in nullifying the roll. At resonance frequencies, the fin would work most effectively.

\subsection{Control algorithm using frequency based coefficients}

The algorithm uses an inbuilt function namely, the Harmonic Distortion Analyzer in LabVIEW, to obtain the dominant frequency in the measured response signal. From the time based roll angle data, the virtual instrumentation performs three functions namely, (i) the differentiation for roll velocity (ii) the second differentiation for roll acceleration and (iii) the frequency detection using the Harmonic Distortion Analyzer. A built-in function for single channel data is used for the above purpose. It typically functions from within a "for loop" or "while loop". After analysis, the fundamental frequency is obtained in the "detected fundamental frequency" terminal. The time period or frequency value is made use of in the polynomial equations formulated for representing the virtual mass moment of inertia and $\mathrm{B}$, the damping moment. Values of A and B are now substituted in the roll equation, which in turn gives the ideal lift moment to be generated by the fins with their known characteristic fin angle and area of surface. Knowing the required fin moment, or the maximum possible fin moment within the limitation of stall angle, the best possible fin angle orientation is obtained.

This control algorithm is independent of the limitation of using only the fixed resonance values of A and $\mathrm{B}$. The algorithm is a refinement of the traditional limited discrete coefficients used in the control algorithm with three zones of choice i.e., before resonance, at resonance or after resonance values. Based on this control logic, the stabilized roll motion has been obtained through the control loop for the simulated random wave. The results are shown in Figure 9a, 9b, 9c.

Though in principle, the resonance frequency based control algorithm works practically well with full control being established in the second feedback control loop, this frequency linked control algorithm works with more mathematically precise control logic. 


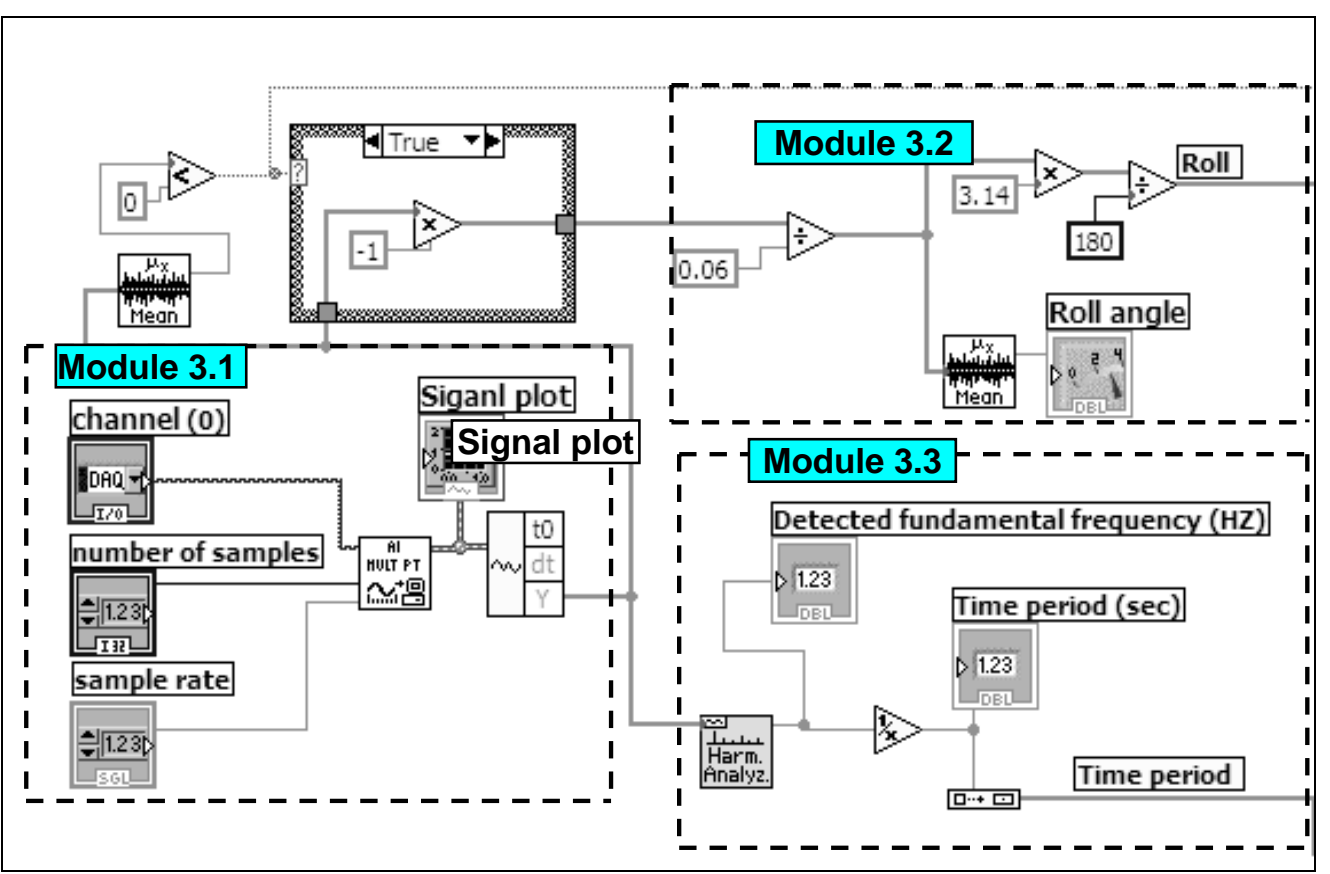

Figure 8a: Virtual instrumentation program in modular parts (part 1 of 3 )

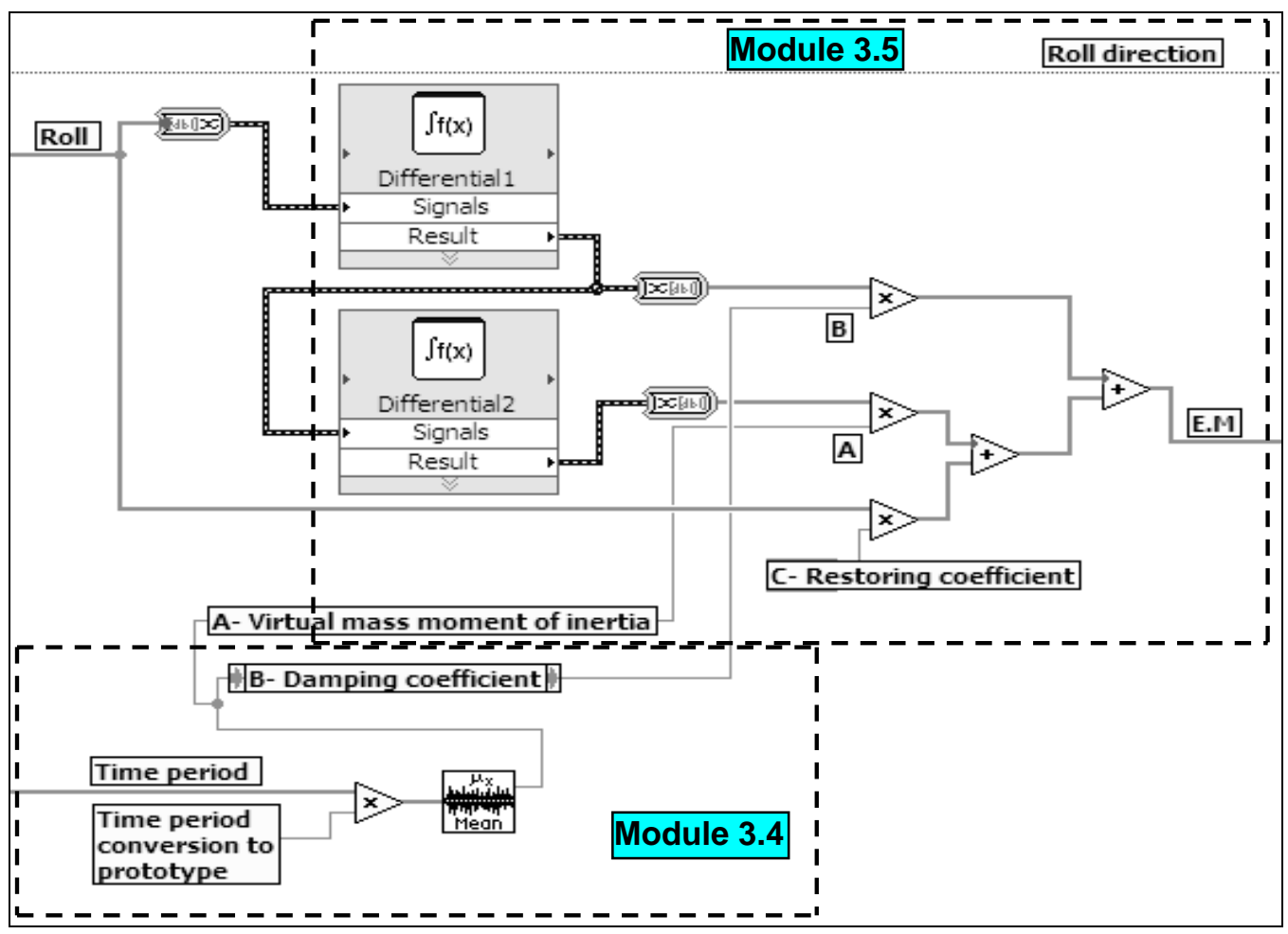

Figure 8b: Virtual instrumentation program in modular parts (part 2 of 3 ) 


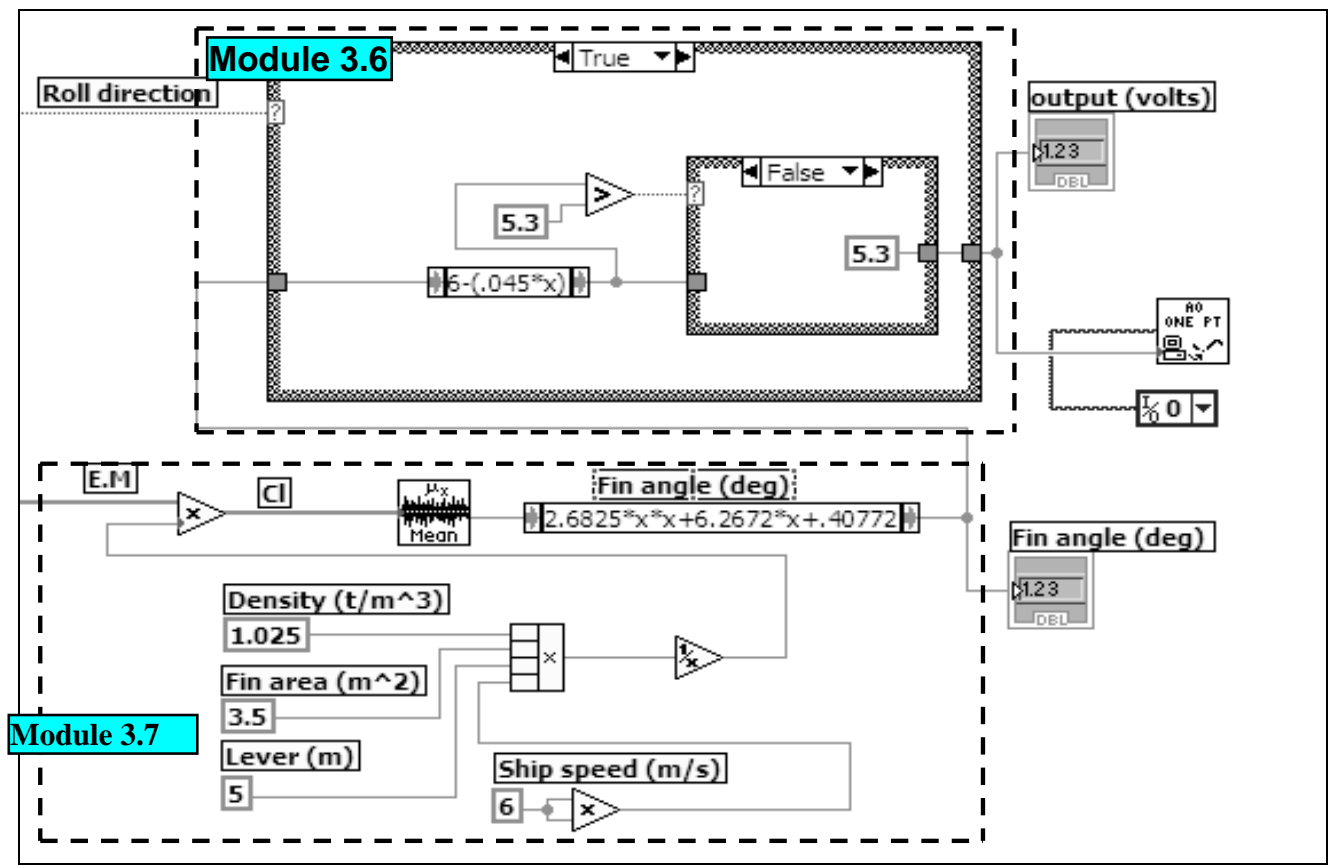

Figure 8c: Virtual instrumentation program in modular parts (part 3 of 3)

The modules for explanation purpose are divided as follows:

3.1- Data acquisition for roll angle

3.2- Roll angle conversion

3.3- Frequency detector

3.4- Estimation of hydrodynamic coefficients

3.5- Time derivative for roll velocity and roll acceleration, exciting moment calculation

3.6- Interpretation of fin angle in degree

3.7- Calculation of polarity and magnitude of control signal

Note:- In module 3.7 (see Fig.8c), the fin lift coefficient versus fin angle characteristic as shown in Fig. 3, has been input in the form of a best fit quadratic equation, the function representing fin angle for a required fin lift coefficient $\mathrm{x}$.

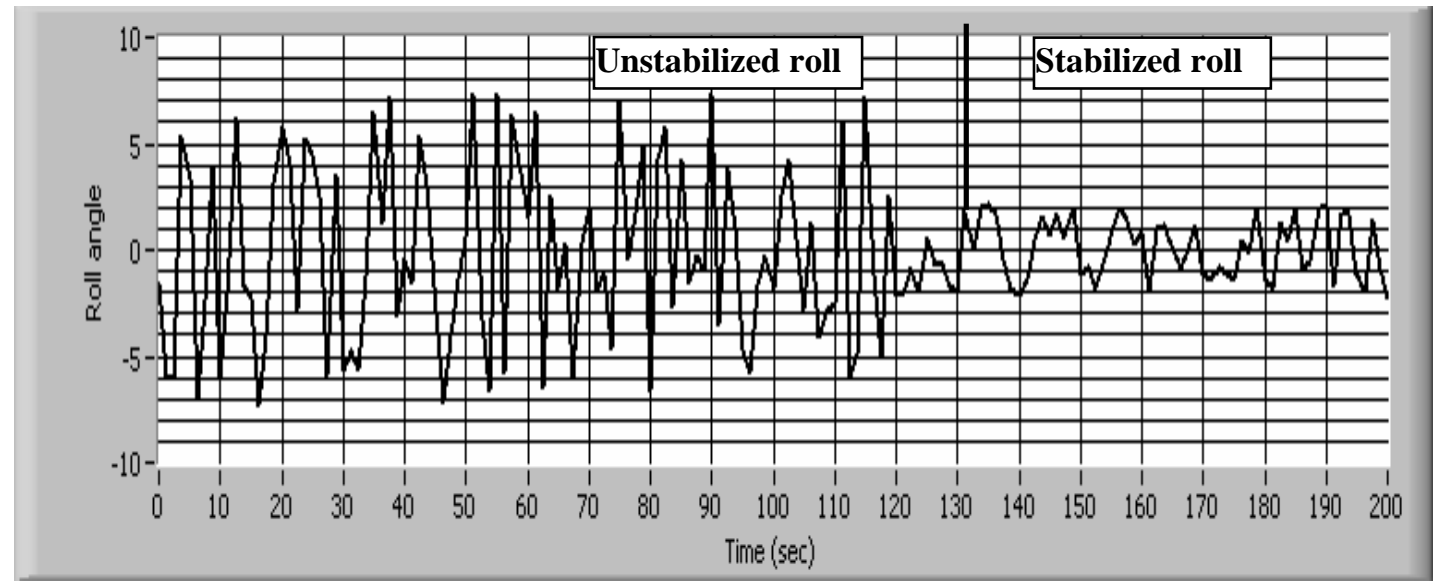

Figure 9a: Simulated roll motion stabilization (ship speed 12knots) 


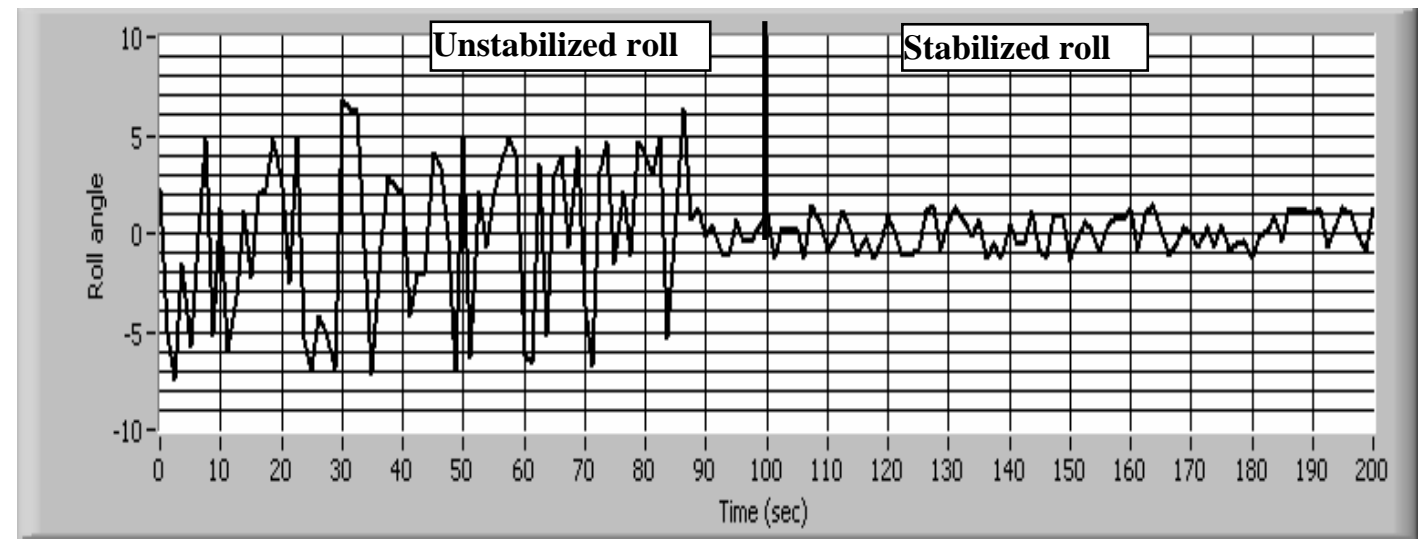

Figure 9b: Simulated roll motion stabilization (ship speed 16knots)

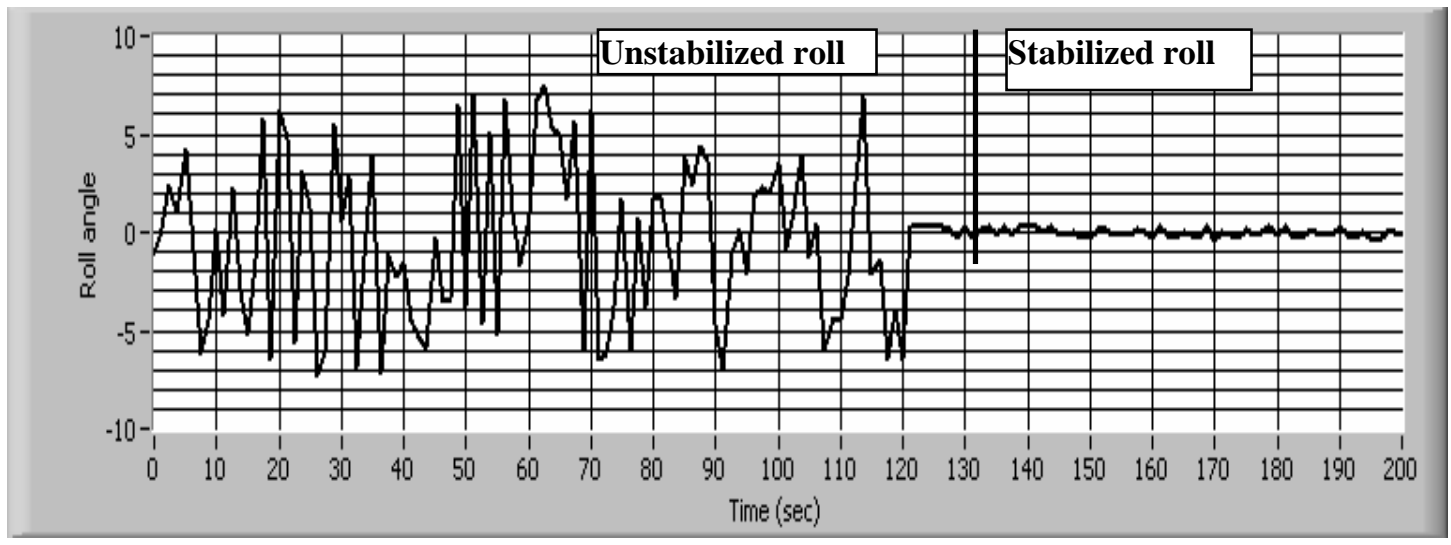

Figure 9c: Simulated roll motion stabilization (ship speed 20knots)

\section{Results and Conclusion}

A non-traditional approach for ship roll motion stabilization based on assessment of the hydrodynamic coefficients of the vessel and including those of the fin has been designed and analyzed. The use of virtual instrumentation minimizes the use of enormous hardware involved in the controllers and instrumentation panels, which otherwise make maintenance and troubleshooting difficult. The use of two control algorithms is demonstrated viz.,

(i) based on fixed frequency hydrodynamic coefficients and

(ii) frequency dependent hydrodynamic coefficients. Simulation studies show the effectiveness in both cases.

The studies for different speeds in irregular roll conditions demonstrate the effectiveness of the roll stabilization system.

In conclusion, the virtual instrumentation concept has been demonstrated to work effectively for the ship roll motion stabilization. It provides a feedback control system with adequate flexibility for changes and fine-tuning of the control logic. 
Table. 3 Error and resultant residual roll angle at different frequencies

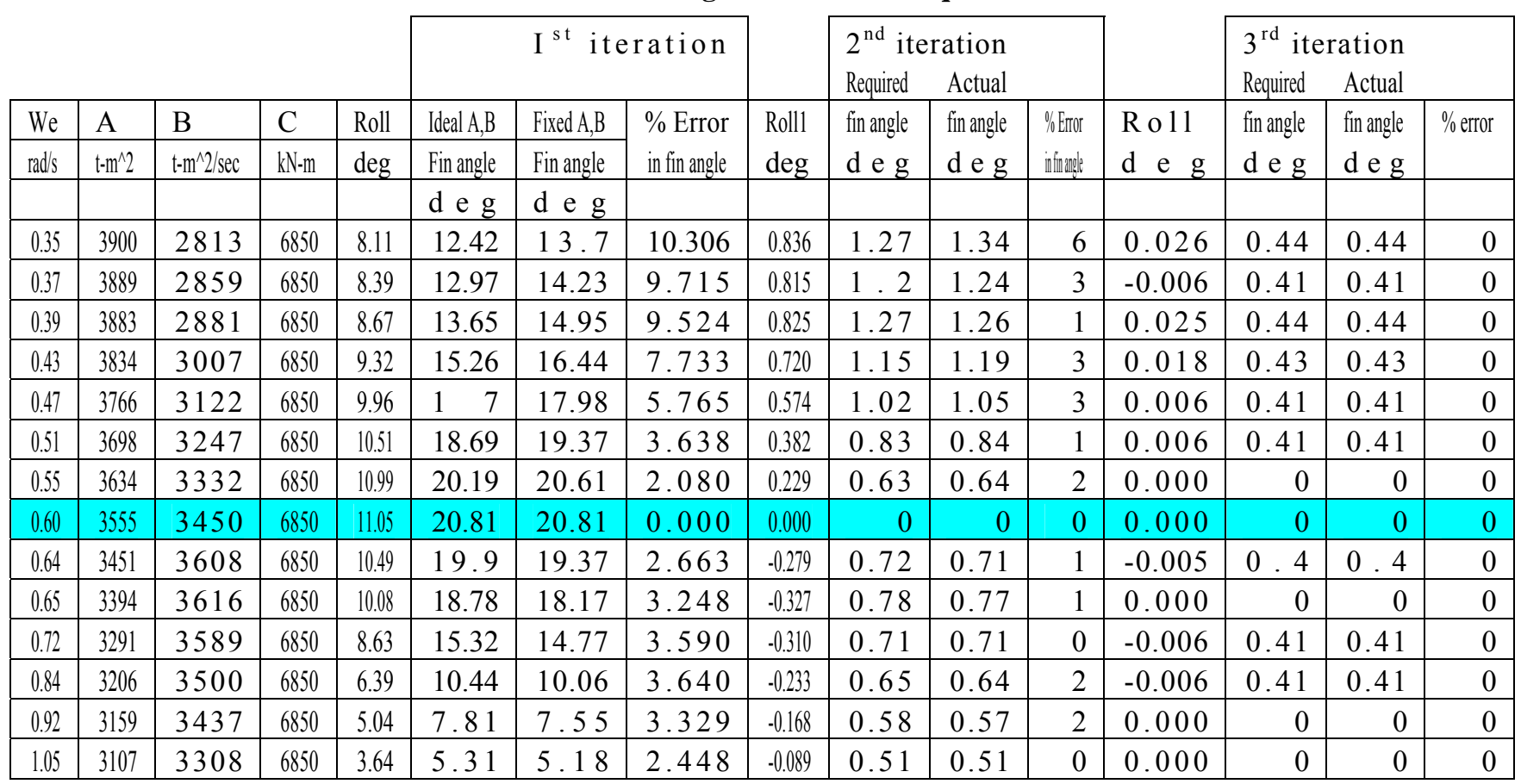

Time elapsed due to

Time elapsed $=20 \mathrm{~ms}$

fin movement through $13.7^{0}=200 \mathrm{~ms}$

Natural frequency of $\mathrm{roll}=0.6 \mathrm{rad} / \mathrm{s}$ 


\section{References}

Conolly, J. E. (1968) Rolling and its stabilization by active fins, Transactions of the Royal institute of Naval Architects, 111, $21-48$.

Gunsteren, F. F. V. (1974) Analysis of roll stabilizer performance, International Shipbuilding Progress, $21,125-146$

Korkut, E., Atlar, M. and Incecik, A. (2004) An experimental study of motion behaviour with an intact and damaged Ro-Ro ship model. Ocean Engineering , 31, 483-512

Lewis, E. V. Principles of Naval Architecture Second revision Vol. III Motions in waves and Controllability, The Society of Naval Architecture and Marine Engineers, Jersy City, NJ, 1989

Lloyd, A.R.J.M. (1974) Roll stabilizer fins: A design procedure, The Royal Institute of Naval Architects, 117, 233 - 254

Rahman, J. and Pichlik, H. LabVIEW applications and solutions, National instruments-Virtual instrumentation series, 1999.

Samoilescu, G. and Radu, S. (2002) Stabilizers and Stabilizing Systems on Ships, $8^{\text {th }}$ International Conference of University day, Tarju Jiu, Romania.

Sheldahl, R.E. and Klimas, P.C. (1981), SAND80-2114, Sandia National Laboratories, Albuquerque, New Mexico.

Sgobbo, J.N. and Parsons, M.G. (1999) Rudder/Fin Roll Stabilization of the USCG WMEC 901 Class vessel. Marine Technology, 36(3), 157-170

Soeding, H. (1988) Berechnung der bewegungen und belastungen von SWATH-schiffen und katamaran im seegang, Institute fur schiffbau der Universitat Hamburg, Bericht Nr. 483 (in German)

Tsuyoshi, K. Nishikido, S. and Wada, Y.(1994) Effect of Fin-area and Control Methods on Reduction of Roll Motion. Bulletin of the M.E.S.J. (Marine Engineers Society in Japan), 22(1), 25-32 